\title{
A DIGESTÃO DOS INSETOS MASTIGADORES: FISIOLOGIA E POTENCIAL USO NO MANEJO INTEGRADO DE PRAGAS (MIP)
}

\author{
C.P.G. Pinto
}

Universidade Estadual Paulista "Júlio de Mesquita Filho" (UNESP) - Faculdade de Ciências Agrárias e Veterinárias - Campus Jaboticabal, SP, Brasil. E-mail: ciro.pedro@ufpel.edu.br

\section{RESUMO}

Os insetos são organismos bastante explorados para estudos a respeito de funções digestivas, particularmente pelo fato de que há espécies adaptadas aos mais diversos habitats e hábitos alimentares. A compreensão da fisiologia digestiva dos insetos nos permite aplicar tais conhecimentos no manejo de pragas. Este trabalho teve por objetivo abordar os principais aspectos da digestão dos insetos mastigadores e inferir como tal conhecimento pode auxiliar no futuro do controle de pragas. Como regra geral, insetos mastigadores possuem estruturas especializadas para a digestão de grandes polímeros como amido, celulose e proteínas insolúveis. A membrana peritrófica é um item chave no processo digestivo dos insetos mastigadores, pois além de proteger a epiderme contra lesões mecânicas do bolo alimentar também é responsável pela compartimentalização dos processos enzimáticos e pela permeabilidade das enzimas e substâncias digeridas ao espaço ectoperitrófico. Essa estrutura é alvo de importantes tecnologias no controle de pragas, como as proteínas Bt. Mesmo com todo o conhecimento científico, o trato digestivo é pouco explorado na busca de novos mecanismos de ação, mas, espera-se que, com as novas tecnologias, o trato digestivo dos insetos mastigadores se torne um alvo importante para a ampliação das opções no Manejo Integrado de Pragas (MIP).

PALAVRAS-CHAVE: enzima, membrana peritrófica, mesêntero. 


\section{ABSTRACT}

\section{THE DIGESTION OF CHEWING INSECTS: PHYSIOLOGY AND POTENTIAL USE IN INTEGRATED PEST MANAGEMENT (IPM).}

Insects are organisms widely explored for studies on digestive functions, particularly because there are species adapted to the most diverse habitats and eating habits. Understanding the digestive physiology of insects allows us to apply such knowledge in pest management. This work aimed to address the main aspects of the digestion of chewing insects and how such knowledge can help in the future of pest control. As a general rule, chewing insects have specialized structures for the digestion of large polymers such as starch, cellulose and insoluble proteins. The peritrophic membrane is a key element in the digestive process of masticatory insects, because in addition to protecting the epidermis against mechanical lesions of the food cake, it is also responsible for the compartmentalization of the enzymatic processes and the permeability of enzymes and substances digested to the ectoperitrophic space. This structure is the target of important technologies in pest control, such as Bt proteins. Even with all scientific knowledge, the digestive tract is little explored in the search for new mechanisms of action, but it is hoped that with the new technologies, the digestive tract of chewing insects will become an important target for the expansion of the options in Integrated Pest Management (IPM).

KEYWORDS: enzyme, peritrophic membrane, midgut.

\section{INTRODUÇÃO}

Os insetos são excelentes modelos para estudos de funções intestinais, pois existem espécies adaptadas a quase todos os habitats e hábitos alimentares. Assim, há a percepção de que o intestino é a melhor interface entre o inseto e o seu ambiente. O entendimento dos processos digestivos é essencial para o desenvolvimento de métodos de controle que agem no trato digestivo, como por exemplo, o uso de plantas transgênicas contra insetos fitófagos (CARRIÈRE; CRICKMORE; TABASHNIK, 2015).

Existe uma grande diversidade de substratos alimentares para os insetos, que podem alimentar-se de qualquer substância orgânica natural, tais como folhas, frutos, xilema, sangue, madeira e lã, entre outros. Apesar da diversidade alimentar, as fontes finais de energia são as mesmas para todos os organismos heterotróficos: os carboidratos, os lipídios e as proteínas (GULLAN et al., 2007). 
Os insetos hemimetábolos mastigadores são, no geral, filogeneticamente mais basais do que os insetos sugadores (MISOF et al., 2014), os quais, pelo processo de adaptação, sofreram alterações nas suas peças bucais, levando a uma diferenciação morfológica drástica para suprir suas necessidades funcionais. Além da morfologia das peças bucais e do trato digestivo, insetos sugadores e mastigadores são muito diferentes no que tange ao conteúdo de enzimas digestivas (TERRA; FERREIRA, 2012).

Em insetos mastigadores, a maior parte das fontes de energia requeridas são polímeros. Os polímeros são cadeias de subunidades iguais ou semelhantes que podem se alternar ou não. Dentre os principais polímeros utilizados pelos insetos para sua alimentação estão o amido e a celulose, formados por unidades de glicose, por ligações $\alpha$ e $\beta$, respectivamente, hemiceluloses, as quais são monossacarídeos unidos por ligações $\beta$, e proteínas, que são compostas por cadeias de aminoácidos.

A maior parte da absorção dos nutrientes, especialmente aminoácidos, é realizada no intestino médio dos insetos. Nesse local, tanto ocorre a secreção de enzimas como a absorção das partículas em solução, sendo que ambos os processos são realizados pelas mesmas células (WIGGLESWORTH, 1972). Os cecos gástricos, presentes na porção anterior do intestino médio, também têm a função secretora e absortiva, além de estarem ligados à manutenção dos mi- cro-organismos simbiontes presentes no trato digestivo dos insetos $(\mathrm{ZUCCHI}$ et al., 2012).

Apesar de as enzimas digestivas estarem presentes em sua grande maioria no intestino médio dos insetos, segundo Tamaki et al. (2014), em insetos mastigadores alguns polissacarídeos, como o amido, começam a ser degradados logo na mastigação, por meio de enzimas presentes na saliva.

Outro fator determinante para o sucesso dos insetos mastigadores, além da complexidade enzimática, é a presença da membrana peritrófica, tanto em formas jovens como em adultos (ZHONG et al., 2014). Essa membrana, situada no mesêntero, consiste primariamente de quitina e proteínas. Ela é forte o suficiente para suportar a digestão e prover proteção contra a força abrasiva das partículas do alimento e o ataque de patógenos entéricos (AGRAWAL et al., 2014). Outras funções fisiológicas importantes para a digestão dos insetos, que são atribuídas à membrana peritrófica, são a compartimentalização de enzimas digestivas e/ou produtos da digestão, neutralização de toxinas ingeridas e prevenção a parasitas, bactérias e infecções virais (HEGEDUS et al., 2009).

Um fato importante a ressaltar sobre a membrana peritrófica é em relação às tecnologias Bt. As proteínas Bt sintetizadas pelas plantas transgênicas rompem a membrana peritrófica dos insetos alvo (FIUZA; POLANCZYK; CRICKMORE, 2017) antes da subsequente degradação 
da epiderme do mesêntero (DA SILVA et al., 2018). O uso de plantas Bt pode ser considerado ecologicamente amigável devido à especificidade das toxinas sobre as pragas, pela redução da aplicação de inseticidas (ÁLVARES-ALFAGEME et al., 2009) e seletividade a inimigos naturais (MEISSLE et al., 2005; FERRY et al. 2006, DE BORTOLI et al., 2017).
Diante do exposto, o objetivo deste trabalho é abordar os principais aspectos relacionados com a fisiologia da digestão nos insetos mastigadores, suas funções, órgãos, mecanismos e enzimas responsáveis. Além disso, é abordado como é possível explorar o trato digestivo de insetos mastigadores na busca de estratégias de controle de pragas.

\section{ASPECTOS FISIOLÓGICOS E MORFOLÓGICOS ENVOLVIDOS NA DIGESTÃO DE INSETOS MASTIGADORES}

\subsection{Ph e compartimentalização das enzimas digestivas}

O mesêntero é o principal órgão digestivo dos insetos mastigadores. Dados recentes indicam que os processos enzimáticos nessa porção do trato digestivo estão divididos temporal e espacialmente (MARIANES, SPRADLING, 2013; MORI; YOSHINAGA, 2018). Os mecanismos de proteção responsáveis pelo $\mathrm{pH}$ e potencial redox, atividade enzimática, absorção de nutrientes e a função excretora estão compartimentalizados em regiões específicas e permitem uma sequência eficiente de quebra dos polímeros em moléculas menores, utilizáveis pelo organismo como nutrientes.

A digestão dos insetos da ordem Blattaria é muito estudada devido à sua complexidade enzimática. $\mathrm{O}$ pH do lúmen de Rhyparobia maderae (Fabricius) (Blattaria: Blaberidae) torna-se alcalino na direção anteroposterior do mesêntero (ENGELMANN; GERAERTS, 1980). A compartimentalização do pH em R. maderae é acompanhada pela organização espacial de enzimas proteolíticas. Praticamente todas as enzimas que digerem caseína foram encontradas na porção endoperitrófica do mesêntero. Em Periplaneta americana (Linnaeus) (Blattaria: Blattidae), ao contrário, a atividade das quimotripsinas predominam nos cecos gástricos (BAUMANN, 1990). Conforme Tamaki et al. (2014), a característica mais marcante das quimotripsinas de $P$. americana é a resistência à inativação. Essa resistência foi observada como uma característica de quimotripsinas de lepidópteros, enquanto como regra geral essas substâncias nos demais insetos são sensíveis (LOPES et al., 2009).

Em estudos realizados por Elpidina et al. (2001), a organização da digestão na parte anterior e posterior do mesêntero de Nauphoeta cinerea (Olivie) (Blattaria: 
Blattidae) é diferente. A compartimentalização da digestão é baseada em um estreito gradiente de $\mathrm{pH}$ e uma distribuição desigual de proteinases e amilases. A acidez no mesêntero dessa espécie diminui no sentido anteroposterior, o que é um padrão geral nos insetos.

Em $P$. americana, o estomodeo é o maior compartimento do trato digestivo, onde ocorre a maior atividade de amilase e a-glicosidase, sendo aproximadamente $60 \%$ para cada enzima, indicando a importância do estomodeo na digestão dos carboidratos (TAMAKI et al., 2014). A digestão inicial das proteínas também ocorre no estomodeo, sendo que a maioria das enzimas encontrada nesse compartimento possui atividade proteolítica (LOPES; TERRA, 2003). É importante salientar que as enzimas encontradas no estomodeo são produzidas em outros locais, especialmente no mesêntero, pois a origem do estomodeo é ectodérmica, o que confere uma estrutura cuticular.

Em insetos Polineopteros (Dictioptera, Phasmidia e Orthoptera) (MISOF et al., 2014), a maioria da digestão dos alimentos ocorre no estomodeo, sendo que o bolo alimentar é propelido, por movimentos peristálticos, para o mesêntero, onde ocorre a digestão final e a absorção dos monômeros. A saliva tem enzimas amilases, que possuem uma importância variável na digestão dos carboidratos. A porção anterior do mesêntero é ácida e possui alta atividade de carboidrases, enquanto na parte posterior do mesêntero o $\mathrm{pH}$ é alcalino e possui alta atividade de proteases (WOODRING et al., 2007).

Assim que os polímeros são digeridos e transformados em moléculas menores, pequenas o suficiente para passar pela membrana peritrófica, eles misturam-se às enzimas digestivas do espaço ectoperitrófico. Este espaço é compreendido entre a membrana peritrófica e as células epiteliais. Neste espaço as moléculas que estão sofrendo processo de digestão se movimentam no sentido contrário do fluxo endoperitrófico. Por fim, os nutrientes são absorvidos pelas células epiteliais, sendo de grande importância para isso os cecos gástricos, os quais são invaginações presentes na região anterior do mesêntero (BIAGIO et al., 2009).

A digestão nos grilos difere dos gafanhotos somente pelo fato de apresentar mais enzimas de membrana, um grande envolvimento do mesêntero na digestão de proteínas e pela ocorrência da reciclagem de enzimas, tanto em insetos bem alimentados como em insetos submetidos a déficit de alimento (BIAGIO et al. 2009).

Em larvas de Dermestes maculatus De Geer (Coleoptera: Dermestidae) o alimento ingerido é digerido em primeiro lugar por enzimas que penetram no espaço endoperitrófico, em seguida, por enzimas que atuam sobre o material no espaço ectoperitrófico, e, finalmente, os alimentos entram nas células do epitélio (CALDEIRA et al., 2007) 


\subsection{Membrana peritrófica}

A maioria dos insetos produz a membrana peritrófica, com exceção de insetos sugadores como hemípteros e adultos de lepidópteros (PETERS, 2012; GAZARA et al., 2017). Em outros grupos, a membrana peritrófica é formada apenas quando os insetos se alimentam, como fêmeas de mosquito após se alimentarem de sangue (LEHANE, 1997). No caso dos sugadores, que não possuem membrana peritrófica, outra membrana é encontrada, a chamada membrana microvilar. Esta membrana possui uma função análoga à membrana peritrófica, mas é adaptada aos hábitos alimentares dos insetos mastigadores (SILVA et al., 2004; GAZARA et al., 2017).

Nos últimos anos, aumentou o entendimento a respeito da membrana peritrófica, chegando a conclusões importantes sobre a sua constituição e de como suas proteínas estruturais a mantém intacta mesmo com a abrasão do bolo alimentar (BOLOGNESI; TERRA; FERREIRA; 2008). Os novos modelos têm mostrado uma interessante relação entre a estrutura da membrana peritrófica e os processos bioquímicos e fisiológicos do organismo dos insetos (HEGEDUS et al., 2009).

As enzimas digestivas devem permear a membrana peritrófica para estender o processo digestivo ao espaço endoperitrófico, assim como produtos intermediários da digestão devem atravessar a membrana na direção inversa para serem processados no espaço ectoperi- trófico antes de serem finalmente absorvidos pelas células epiteliais do mesêntero. Assim, a membrana peritrófica dos insetos pode ser considerada como uma complexa barreira física que mantém o bolo alimentar separado do contato com as células epiteliais, dessa forma, impedindo injúrias mecânicas (AGRAWAL et al., 2014).

Existem inúmeras outras funções que podem ser atribuídas à membrana peritrófica, dentre elas pode-se incluir a proteção contra micro-organismos infecciosos e compostos tóxicos presentes no substrato alimentar. Devido ao seu íntimo envolvimento nos processos digestivos e papel como uma primeira linha de defesa contra patógenos ingeridos, a membrana peritrófica é um atraente alvo para estratégias de manejo de pragas. Os compostos que interagem com a membrana peritrófica têm o potencial de afetar suas propriedades físico-químicas e biológicas. Os efeitos podem ser sutis, tais como a diminuição da eficiência digestiva, impedindo absorção de nutrientes ou descompartimentando os processos digestivos. Atacando a membrana peritrófica, haverá efeitos graves na fisiologia dos insetos e é possível aumentar a eficácia de toxinas e agentes patogênicos que precisam atravessar a membrana peritrófica para acessar o epitélio do intestino médio (HEGEDUS et al., 2009).

Parasitas de insetos e patógenos produzem enzimas hidrolíticas, tais como proteases e quitinases, que facilitam a penetração na membrana peritró- 
fica (BUTT et al., 2016). Além disso, em resposta ao dano por insetos herbívoros, plantas também produzem enzimas que corrompem a membrana peritrófica, prejudicando a alimentação dos insetos (RAO et al., 2014).

\section{TECNOLOGIAS EMERGENTES}

Proteinases de plantas transgênicas são viáveis para serem utilizadas na engenharia de resistência de plantas (LIU et al. 2006). Por exemplo, linhagens de Zea mays resistentes a Spodoptera frugiperda (J.E. Smith) (Lepidoptera: Noctuidae) produzem cisteína proteases, as quais corrompem a integridade da membrana peritrófica e reduzem o potencial de alimentação das lagartas (MOHAN et al., 2006).

Existe grande potencial de sinergismo entre transgênicos e controle biológico, pois, com a disfunção do aparelho digestivo, aumentam as chances de infecção por parte de patógenos ou toxinas destes (MOHAN et al, 2008). É interessante salientar que importantes tecnologias, como o Bt, no geral apresentam uma alta seletividade a inimigos naturais. Meissle, Vojtech e Poppy (2005) verificaram que não há evidências de que o predador Poecilus cupreus (Linné) (Coleoptera: Carabidae) evita presas contaminadas com proteínas Bt em testes de comparação com presas não contaminadas. Similarmente, Ferry et al. (2006) concluíram que o predador Pterostichus madidus (Fabricius) (Coleoptera: Carabidae) alimentado com larvas intoxicadas não sofreu nenhuma alteração aparente no seu ciclo. Esses estudos indicam a importância de se conhecer os hábitos alimentares dos insetos, assim como sua fisiologia, para que não se infira erroneamente aspectos das plantas transgênicas sobre os inimigos naturais. Isto possibilita o melhor uso dessa tecnologia e do controle biológico, tanto natural como o aplicado.

A tecnologia do RNA interferente (RNAi) tem sido amplamente estudada, tanto no sentido de se entender o funcionamento de proteínas ou rotas metabólicas, quanto na busca de novas tecnologias para o controle de pragas (JOGA et al., 2016). Essa tecnologia baseia-se no silenciamento gênico pós-transcricional frente a aplicação de uma fita dupla de RNA com a sequência complementar ao RNA alvo, o qual será reconhecido e clivado por uma maquinaria celular específica (ZOTTI; SMAGGHE, 2015). Novas aplicações do RNAi têm sido amplamente investigadas quanto ao nocaute de proteínas responsáveis pela manutenção da membrana peritrófica (CHEN e al., 2008; CHEN et al., 2010; SANDOVAL-MOJICA; SCHARF, 2016).

A quitina é um polímero rígido que constitui a base estrutural da membrana peritrófica. A porosidade da membrana peritrófica, essencial no controle da di- 
gestão de insetos, é mediada por quitinases (ZHU et al., 2008), que por sua vez são naturalmente controladas por RNAi. O nocaute dessas quitinases por RNAi exógeno causa a redução em mais de $50 \%$ do peso corporal de Tribolium castaneum (Herbst) (Coleoptera: Tenebrionidae) (KHAJURIA et al., 2010). Os RNAi podem ser produzidos pelas plantas, sendo induzidos por meio da transgenia (BAUM et al., 2007).

Além do RNAi, a quitina presente na membrana peritrófica dos insetos mastigadores pode ser alvo de enzimas qui- tinases, como aquelas provenientes de actinobactérias (ROSSI et al., 2015). Como o mesêntero dos mastigadores é um ambiente alcalino, isto favorece a hidrólise da quitina pelas quitinases, corrompendo, assim, a membrana peritrófica. É possível a utilização de quitinases como um gene recombinante para a defesa de plantas contra insetos, pois já foi comprovado que plantas de tabaco transgênicas, contendo uma quitinase recombinante, foram mais tóxicas para Heliothis virescens (Fabricius) (Lepidoptera: Noctuidae) (ROSSI et al., 2012).

\section{CONCLUSÕES}

As diferenças morfológicas entre as espécies de insetos refletem as suas diferenças fisiológicas. As enzimas digestivas, apesar de muito semelhantes nas várias espécies de insetos, são muito específicas quanto ao hábito alimentar de cada inseto. Os insetos evoluíram não apenas morfologicamente e suas enzimas digestivas também se adaptaram às suas necessidades.

Novos métodos de controle de pragas podem ser desenvolvidos fazendo o uso do conhecimento sobre os processos digestivos dos insetos. Métodos de controle com foco na disfunção do trato digestivo dos insetos mastigadores já têm sido utilizados, como é o caso das proteínas Bt. Já, outros em ascensão, como o RNAi, estão em fase de avaliação. Espera-se que no futuro sejam disponibilizadas plantas transgênicas com diferentes mecanismos de ação, além de outras tecnologias para o controle de pragas. 


\section{AGRADECIMENTOS}

À CAPES, pelo apoio financeiro, e à UFPEL e UNESP-FCAV, pelo suporte técnico-científico.

\section{REFERÊNCIAS}

AGRAWAL, S.; KELKENBERG, M.; BEGUM, K.; STEINFELD, L.; WILLIAMS, C.E.; KRAMER K.J.; BEEMAN R.W.; PARK, Y.; MUTHUKRISHNAN, S.; MERZENDORF$\mathrm{ER}, \mathrm{H}$. Two essential peritrophic matrix proteins mediate matrix barrier functions in the insect midgut. Journal of Insect Biochemistry and Molecular Biology, v. 49, p. 24-34, 2014. https://doi.org/10.1016/j.ibmb.2014.03.009

ÁLVAREZ-ALFAGEME, F.; ORTEGO, F.; CASTAÑERA, P. Bt maize fed-prey mediated effect on fitness and digestive physiology of the ground predator Poecilus cupreus $L$. (Coleoptera: Carabidae). Journal of Insect Physiology, v. 55, p. 144-150, 2009. https:// doi.org/10.1016/j.jinsphys.2008.10.014

BAUM, J.A; BOGAERT, T.; CLINTON, W.; HECK, G.R.; FELDMANN; P. Control of coleopteran insect pests through RNA interference. Nature Biotechnology, v. 25 p. 132226, 2007. https://doi.org/10.1038/nbt1359

BAUMANN, E. Isolation and partial characterization of a chymotrypsin-like endoprotease from cockroach intestinal system. Insect Biochemistry, v. 20, p. 761-768, 1990. https://doi.org/10.1016/0020-1790(90)90093-A

BIAGIO, F.P.; TAMAKI, F.K.; TERRA, W.R.; RIBEIRO, A.F. Digestive morphophysiology of Gryllodes sigillatus (Orthoptera: Gryllidae). Journal of Insect Physiology, v. 55, p. 1125-1133, 2009. https://doi.org/10.1016/j.jinsphys.2009.08.015

BOLOGNESI, R.; TERRA, W.R.; FERREIRA, C. Peritrophic membrane role in enhancing digestive efficiency: theoretical and experimental models. Journal of Insect Physiology, v. 54, p. 1413-1422, 2008. https://doi.org/10.1016/j.jinsphys.2008.08.002

BUTT, T.M.; COATES, C.J.; DUBOVSKIY, I.M.; RATCLIFFE, N.A. Entomopathogenic fungi: new insights into host-pathogen interactions. In: Advances in Genetics. Academic Press, p. 307-364, 2016.

CALDEIRA, W.; DIAS A.B.; TERRA, W.R.; RIBEIRO, A.F. Digestive enzyme compartmentalization and recycling and sites of absorption and secretion along the midgut of Dermestes maculatus (Coleoptera) larvae. Archives of Insect Biochemistry and Physiolog, v. 64 p. 1-18, 2007. https://doi.org/10.1002/arch.20153 
CARRIÈRE, Y.; CRICKMORE, N.; TABASHNIK, B.E. Optimizing pyramided transgenic Bt crops for sustainable pest management. Nature Biotechnology, v. 33, p. 161, 2015. https://doi.org/10.1038/nbt.3099

CHEN, J.; TANG, B.; CHEN, H.; YAO, Q.; HUANG, X.; CHEN, Z.W. Different functions of the insect soluble and membrane-bound trehalase genes in chitin biosynthesis revealed by RNA interference. PLoS One, v. 5, p. e10133, 2010. https://doi.org/10.1371/ journal.pone.0010133

CHEN, X.; TIAN, H.; ZOU, L.; TANG, B.; HU, J.; ZHANG, W. Disruption of Spodoptera exigua larval development by silencing chitin synthase gene A with RNA interference. Bulletin of Entomological Research, v. 98, p. 613-619, 2008. https://doi. org/10.1017/S0007485308005932

DA SILVA, I.H.S.; GOMÉZ, I.; SÁNCHEZ, J.; DE CASTRO, D.L.M.; VALICENTE, F.H.; SOBERÓN, M.; POLANCZYK, R.A.; BRAVO, A. Identification of midgut membrane proteins from different instars of Helicoverpa armigera (Lepidoptera: Noctuidae) that bind to Cry1Ac toxin. PLoS One, v. 13, n. 12, p. e0207789, 2018. https://doi.org/10.1371/ journal.pone.0207789

DE BORTOLI, S.A.; VACARI, A.M.; POLANCZYK, R.A.; VEIGA, A.C.P.; GOULART, R.M. Effect of Bacillus thuringiensis on parasitoids and predators. In: FIUZA, L.M.; POLANCZYK, R.A.; CRICKMORE, N. (Eds.) Bacillus thuringiensis and Lysinibacillus sphaericus. Springer, Cham, 2017,p. 67-77.

ELPIDINA, E.N.; KONSTANTIN S.V.; VIKTOR A.G.; YULIYA A.R. Compartmentalization of proteinases and amylases in Nauphoeta cinerea Midgut. Archives of Insect Biochemistry and Physiology, v. 48, p. 206-216, 2001. https://doi.org/10.1002/arch.10000

ENGELMANN, F.; GERAERTS W.P.M. The proteases and the protease inhibitor in the midgut of Leucophaea maderae. Journal of Insect Physiology, v. 26 p. 703-710, 1980. https://doi.org/10.1016/0022-1910(80)90044-X

FERRY, N.; MULLIGAN, E.A.; STEWART, C.N.; TABASHNIK, B.E.; PORT, G.R.; GATEHOUSE, A.M.R. Prey-mediated effects of transgenic canola on a beneficial, non-target, carabid beetle. Transgenic Research, v. 15, p. 501-514, 2006. https://doi. org/10.1007/s11248-006-0021-4

FIUZA, L.M.; POLANCZYK, R.A.; CRICKMORE, N. (Eds.). Bacillus thuringiensis and Lysinibacillus sphaericus: Characterization and use in the field of biocontrol. Springer, 2017. 
GAZARA, R.K.; CARDOSO, C.; BELLIENY-RABELO, D.; FERREIRA, C.; TERRA, W.R.; VENANCIO, T.M. De novo transcriptome sequencing and comparative analysis of midgut tissues of four non-model insects pertaining to Hemiptera, Coleoptera, Diptera and Lepidoptera. Gene, v. 627, p. 85-93, 2017. http://dx.doi.org/10.1016/j. gene.2017.06.008

GULLAN, P.J. et al. Os insetos: um resumo de entomologia. Roca, 2007.

HEGEDUS, D.; ERLANDSON, M.; GILLOTT, C.; TOPRAK, U. New insights into peritrophic matrix synthesis, architecture, and function. Annual Review of Entomology, Stanford v. 54, p. 285-302, 2009. https://doi.org/10.1146/annurev.ento.54.110807.090559

JOGA, M.R.; ZOTTI, M.J.; SMAGGHE, G.; CHRISTIAENS, O. RNAi efficiency, systemic properties, and novel delivery methods for pest insect control: What we know so far. Frontiers in Physiology, v. 7, p. 1-14, 2016. https://doi.org/10.3389/fphys.2016.00553

KHAJURIA, C.; BUSCHMAN, L.L.; CHEN, M.S.; MUTHUKRISHNAN, S.; ZHU, K.Y. A gut-specific chitinase gene essential for regulation of chitin content of peritrophic matrix and growth of Ostrinia nubilalis larvae. Insect Biochemistry and Molecular Biology, v. 40, p. 621-629, 2010. https://doi.org/10.1016/j.ibmb.2010.06.003

LEHANE, M.J. Peritrophic matrix structure and function. Annual Reviews of Entomology, v. 42 p. 525-50, 1997. https://doi.org/10.1146/annurev.ento.42.1.525

LIU, S.; LI, H.; SIVAKUMAR, S.; BONNING, B.C. Virus-derived genes for insect-resistant transgenic plants. Advances in Virus Research, v. 68, p. 427-57, 2006. https://doi. org/10.1016/S0065-3527(06)68012-3

LOPES, A.R.; SATO, P.M.; TERRA, W.R. Insect chymotrypsins: chloromethyl ketone inactivation and substrate specificity relative to possible coevolutional adaptation of insects and plants. Archives of Insect Biochemistry and Physiology, v. 70, p. 188-203, 2009. https://doi.org/10.1002/arch.20289

LOPES, A.R.; TERRA, W.R. Purification, properties and substrate specificity of a digestive trypsin from Periplaneta americana (Dictyoptera) adults. Insect Biochemistry and Molecular Biology, v. 33, p. 407-415, 2003. https://doi.org/10.1016/S09651748(03)00003-1

MARIANES, A.; SPRADLING, A.C. Physiological and stem cell compartmentalization within the Drosophila midgut. Elife, v. 2, p. e00886, 2013. https://doi.org/10.7554/ eLife.00886 
MEISSLE, M.; VOJTECH, E.; POPPY, G.M. Effects of Bt maize-fed prey on the generalist predator Poecilus cupreus L. (Coleoptera: Carabidae). Transgenic Research, v. 14, p.123-132, 2005. https://doi.org/10.1007/s11248-004-6458-4

MISOF, B.; LIU, S.; MEUSEMANN, K.; PETERS, R.S.; DONATH, A.; MAYER, C.; ...; NIEHUIS, O. Phylogenomics resolves the timing and pattern of insect evolution. Science, n. 346, p. 763-767, 2014. https://doi.org/10.1126/science.1257570

MOHAN, S.; MA, P.W.K.; PECHAN, T.; BASSFORD, E.R.; WILLIAMS W.P.; LUTHE, D.S. Degradation of the Spodoptera frugiperda peritrophic matrix by an inducible maize cysteine protease. Journal of Insect Physiology, n. 52, p. 2-28, 2006. https://doi. org/10.1016/j.jinsphys.2005.08.011

MOHAN, S.; MA, P.W.K.; WILLIAMS, W.P.; LUTHE, D.S. A naturally occurring plant cysteine protease possesses remarkable toxicity against insect pests and synergizes Bacillus thuringiensis toxin. PLoS One, v. 3 p. 1786, 2008. https://doi.org/10.1371/ journal.pone.0001786

MORI, N.; YOSHINAGA, N. Function of the lepidopteran larval midgut in plant defense mechanisms. In: Chemical Ecology of Insects, CRC Press, p. 28-54, 2018.

PETERS, W. Peritrophic membranes. Springer Science \& Business Media, 2012.

RAO, R.; FIANDRA, L.; GIORDANA, B.; DE EGUILEOR, M.; CONGIU, T. AcMNPV ChiA protein disrupts the peritrophic membrane and alters midgut physiology of Bombyx mori larvae. Insect Biochemistry and Molecular Biology, v. 34, p. 05-13, 2014. https://doi.org/10.1016/j.ibmb.2004.08.002

ROSSI, G.D.; ZUCCHI, T.D.; GUIDOLIN, A.S.; PERUCHI, A.; CÔNSOLI, F.L. Chitin-degrading enzymes from an actinomycete ectosymbiont of Acromyrmex subterraneus brunneus (Hymenoptera: Formicidae). Annals of Microbiology, v. 65, p. 565-574, 2015. https://doi.org/10.1007/s13213-014-0892-1

ROSSI, G.D.; LABATE, M.T.; LABATE, C.A.; VINSON, S.B.; CÔNSOLI, F.L. Characterization of a Toxoneuron nigriceps (Viereck) (Hymenoptera: Braconidae) - derived chitinase and its potential for pest control. Pesticide Biochemistry and Physiology, v. 104, p. 96-102, 2012. https://doi.org/10.1016/j.pestbp.2012.07.005

SANDOVAL-MOJICA, A. F.; SCHARF, M. E. Silencing gut genes associated with the peritrophic matrix of Reticulitermes flavipes (Blattodea: Rhinotermitidae) increases susceptibility to termiticides. Insect Molecular Biology, v. 25, p. 734-744, 2016. https:// doi.org/10.1111/imb.12259 
SILVA, C.P; SILVA. J.R.; VASCONCELOS, F.F.; PETRETSKI M.D.; DAMATTA R.A. Occurrence of midgut perimicrovillar membranes in paraneopteran insect orders with comments on their function and evolutionary significance. Arthropod Structure \& Development, v. 33, p. 139-48, 2004. https://doi.org/10.1016/j.asd.2003.12.002

TAMAKI, F.; PIMENTEL, A.; DIAS, A.; CARDOSO, A.; RIBEIRO A.; FERREIRA, C.; TERRA. W. Physiology of digestion and the molecular characterization of the major digestive enzymes from Periplaneta americana. Journal of Insect Physiology, v. 70, p. 22-35, 2014. https://doi.org/10.1016/j.jinsphys.2014.08.007

TERRA, W.R.; FERREIRA, C.L. Molecular and evolutionary physiology of insect digestion. In: PANIZZI A.R, PARRA J.R.P (Eds.) Insect Bioecology and Nutrition for Integrated Pest Management, p. 93-119, 2012.

WIGGLESWORTH, V.B. The Principles of Insect Physiology, Methuen, London, $7^{\text {th }}$ ed. 434 p., 1972.

WOODRING, J.; HOFMAN, K.; LORENZ, M.W. Activity, release and flow of digestive enzymes in the cricket, Gryllus bimaculatus. Physiological Entomology, v. 32, p. 56-63, 2007. https://doi.org/10.1111/j.1365-3032.2006.00541.x

ZHONG, X.W.; WANG, X.H.; TAN, X.; XIA, Q.Y.; XIANG, Z.H.; ZHAO, P. Identification and molecular characterization of a chitin deacetylase from Bombyx mori peritrophic membrane. International Journal of Molecular Sciences, v. 15, p. 1946-1961, 2014. https://doi.org/10.3390/ijms15021946

ZHU, Q.; ARAKANE, Y.; BEEMAN, R.W.; KRAMER, K.J.; MUTHUKRISHNAN, S. Functional specialization among insect chitinase family genes revealed by RNA interference. Proceedings of the National Academy of Sciences, v. 105, n. 18, p. 66506655, 2008. https://doi.org/10.1073/pnas.0800739105

ZOTTI, M.J.; SMAGGHE, G. RNAi technology for insect management and protection of beneficial insects from diseases: Lessons, challenges and risk assessments. Neotropical Entomology, v. 44, n. 3, p. 197-213, 2015. https://doi.org/10.3389/fphys.2016.00553 ZUCCHI, T.D.; PRADO, S.S.; CÔNSOLI, F.L. The gastric caeca of pentatomids as a house for actinomycetes. BMC Microbiology, v. 12, p. 101, 2012. https://doi. org/10.1186/1471-2180-12-101

Recebido em: 30/08/2018

Aprovado em: 31/01/2019 